\title{
Teacher Experiences In Performance Management System (PMS) In Zimbabwe: Focus On Assessment Reviews And Teachers' Response
}

\author{
Wonderful Dzimiri \\ Department of Educational Foundations \\ Management and Curriculum Studies \\ Midlands State University, Zimbabwe \\ Canaan Mkosana \\ Department of Educational Foundations \\ Management and Curriculum Studies \\ Midlands State University, Zimbabwe
}

\begin{abstract}
This study investigated teacher experiences of, and response to the manner they were assessed or appraised in implementation of Performance Management System (PMS) in Zimbabwe amid concerns over difficulties in the determination of the link between an individual's job performance and organizational performance, subjectivity in the conduct of performance appraisals and the interplay of personal biases in performance assessment and ratings. Using mixed methods approach, research designs included the survey, case study and phenomenology. From two randomly selected districts of the Midlands Province, 5.2\% of primary school teachers and 3.5\% of secondary school teachers were randomly sampled from randomly picked schools in the two districts. School heads of sampled schools and district education officers were purposively selected. Data generation tools included questionnaire, semi-structured interviews, document analysis and non-participant observation. Analysis employed descriptive statistics (numbers and corresponding percentages) for quantitative data, and thematic analysis for qualitative data respectively. The major finding was that training on PMS was inadequate for supervisors and teachers. Consequently, teachers and supervisors did not understand what they were expected to do in PMS. Furthermore, school heads' concern lay with summative supervision and enforcement of PMS through coercive, dictatorial approaches akin to policing for compliance. Without adhering to procedure, crisis management combined reviews and appraisal ratings in a single meeting in some cases. Teachers perceived supervisors' role negatively, resulting in teachers cheating or resisting, thus defeating professional development benefits of PMS. Findings point to the need for training and resourcing, or modification of the system to suit context.
\end{abstract}

Key words: performance management; appraisal; teacher supervision; performance ratings; performance assessment.

\section{Situating the Study}

\section{INTRODUCTION}

Swindoll's view that life is $90 \%$ of the choices one makes to react to what happens to him or her (cited in Ringue, 2002) is pertinent. The way school teachers may view the manner they are supervised has a serious bearing on their acceptance to take part in Performance Management System initiatives. On the other hand, the extent to which school heads may be willing to compromise their monopolistic authority over their summative supervisory role, 
and to exclusively temper this role with the de jure clinical responsibility that characterizes PMS is a matter for conjecture, and that too is highly debatable.

Adoption of Performance Management System (PMS) in Zimbabwe civil service came after Zimbabwe's adoption of Brentonn Woods mandated Economic Structural Adjustment Programme (ESAP) in the 1990s with the sole aim of financial accountability and quality assurance and control in the delivery of services such as education. Evidence shows that implementation of PMS in Zimbabwe is fraught with constraints or challenges that negatively affect successful adoption and implementation by teachers. Such are challenges around skills and knowledge of supervisors to include education officers, school heads, deputy heads, heads of departments, teachers in charge and senior teachers charged with dispensing the training to, and supervision of teachers (Dzimiri \& Mkosana, 2015). As Machingambi (2013) observes, poor planning, absence of effective communication, and inadequate funding and training are root sources of challenges bedeviling PMS in Zimbabwe. Yet, key stakeholders' demand for quality education provision and accountability of schools appear as the greatest challenges that schools face (Darling \& Richardson, 2009), and PMS can be viewed as a vehicle towards improvement of teacher performance

Cardno (1999), South African Public Service Commission (2008), and Musingafi (2007) argue that, (a) waiting to receive and receiving the appraisal can be stressful; (b) determining the link between an individual job performance and organizational performance is not easy; (c) if challenged, legal issues can put the organization at risk (d) performance appraisal being conducted by human beings is subject to a number of errors; and (e) as Robbins and de Cenzo (1995, p. 127) argue, "What if you deliberately evaluate an employee you like higher than one you dislike even though the latter is the higher performer? Likewise, what if you avoid identifying development areas for an employee so that his or her political advancement is limited?" These observations point to the subjectivity involved in the assessment aspect of PMS, which is bound to have implications on receptivity by teachers.

The above arguments render focus on PMS's assessment component important as this aspect can determine acceptability by teachers, as well as overall successful implementation of the programme. Performance Management System has become central to the work of teachers in schools world over. Its centrality should, of necessity, derive from the skills training by the school heads and other line managers among whom are the heads of departments, teachers in charge and the senior teachers. The importance of school leaders'/heads' ability to equip their subordinates or followers cannot be over emphasized. This paper seeks to unmask the assessment component of PMS and teacher response to the same. This entails the extent to which heads of schools are fully supported in terms of the knowledge provision so that they are able to successfully implement PMS, especially the assessment part, which requires them to staff develop and supervise others meaningfully. Failure to meet this need creates a problem for the programme as teachers will not have a well mapped vision to follow, which probably results in their being de-motivated, resistance and ultimate rejection of the system.

Given later adoption of PMS by Zimbabwe's education sector and the general expressions of dislike of the system by educators, this study adds a Zimbabwean perspective to the international discourse on PMS, and facilitates insightful understanding of the complexities in implementation of PMS to educational management and leadership practitioners, policy makers and teachers alike. 


\section{THEORETICAL CLARIFICATIONS AND LITERATURE REVIEW}

A sound theoretical lens through which to view appraisals in the framework of PMS is the Goal Setting Theory (GST) that Edwin Locke and Gary Latham developed in the 1960s. According to Miner (2005), in a nutshell, Locke and Latham's GST relates to the relationship between level of indented achievement and the actual level of achievement. The argument is that the existence of specific goals or standards that should be met translates to more pronounced performance effects, than where specific goals were lacking. Arguably, efforts towards a determinate goal should lead to a higher level of interest in the task than with an abstract goal such as "do the best you can. Consequently, appraisers or supervisors can thus lean towards the objectives model of supervision, which might be devoid of the flexibility inherent in the clinical model of supervision that should characterize the review and appraisal meetings. While this is a plausible theory to underpin PMS appraisal processes, we observe arguments that Ayee (2001) raises, that setting targets is shrouded by complexity and controversy in that setting targets and performance evaluation are debatable, controversial and subjective phenomena, especially in the public service such as Zimbabwe's education sector. We therefore sought to unmask Zimbabwe's teacher response to the assessment factor in PMS in Zimbabwe.

Mestry et al. (2009) hold that the essence of PMS is to motivate teachers through professional development, which is a requisite process in any successful implementation of PMS. Ideally, PMS should therefore necessarily enable accurate measurement, monitoring and enhancement of teacher performance and motivation through teacher professional development, recognition and reward (Machingambi, 2013). Robbins (2007) and Sergiovanni and Starrat (1993) warn that in evaluation of performance, the evaluators or appraisers need to be cognisant of their attempt to measure the invisible and the subjective side of measurement, and in the context of schools this process demands extreme caution as issues of validity and objectivity, and reliability emerge. Similarly, The Zimbabwe Public Service Commission's Performance Management instrument has devoted a whole page to traits. Robbins and de Cenzo (1995) argue that an evaluation based on traits such as dependability, confidence and loyalty for example, is inferior. Would an employee described as uncooperative, unreliable, or works under strict supervision, be rated highly if he achieved in all his critical Key Result Areas (KRAs)? If not, Robbins and de Cenzo (1995) would regard the assessment as being inappropriate. Arguably, Machingambi (2013) argues that some employees can be conservative as to set weak goals, or unrealistic as to set over ambitious goals, which ends up distorting performance. The assessor however, is constrained by the objectives model which dictates the direction of his/her assessment and hence, restricting flexibility in the assessment. To further compound the problem, it is stated that "... the performance target assessment shall be based on performance in terms of agreed outputs. Each output identified shall be assigned a weight according to the importance of that output relative to the other outputs" (Zimbabwe, Public Service Commission, 2009, p. 7).

Systems that are designed to bring growth benefits to teachers need to employ user friendly approaches to avert controversial issues that emanate from the many errors that are associated with the process. For example, the halo effect, leniency and similar errors, (Nhundu, 1999; Marr, 2008; Sergiovanni \& Starrat, 1993). Clinical Supervision, which, according to Acheson and Gall (1987 : 13), is "...that supervision focused upon the improvement of instruction by means of systematic cycles of planning, observation and intellectual analysis of actual teaching performance in the interest of rational modification," is a more progressive 
model. However, the interest of this paper lies in assessing the clinical level of the supervision taking place in PMS in the two Districts under investigation.

\section{The Problem}

Assessment of personnel in Performance Appraisal has problems (Robbins \& De Cenzo, 1995). There are areas of conflict arising from the assessment process; "...the discouraging "halo effect' and central tendency in rating teachers; the lack of mechanism to standardize performance for all teachers in all schools and the fact that the school head disagrees with everything teachers do," (Ngwenya, 2002, pp. 12 - 13). The attempts to improve assessment procedures through the use of reports by pupils to assess their teachers has a negative impact because of its tendency to erode teacher confidence and respect by the pupils. The interest of this study lay in establishing whether or not there is any perceived relationship between matters of assessment and teacher's response to Performance Management System. The assessment focus of this paper covers teacher perceptions on the role of the supervisor in Performance Management, the supervision models that are applied during the review and appraisal meetings, the capacity of school heads to do performance management, and what could be the way forward.

\section{METHODOLOGY}

The mixed methods paradigm with its combination of both positivist and constructivist assumptions underpinned the design of this study. Thus the methodology incorporated both objectivist and constructionist epistemological assumptions, which dictated the way we navigated this study. In line with this perspective, the study employed mixed designs incorporating case study, survey and phenomenological, and document review strategies, which allowed us to pursue teacher experiences with the assessment factor of performance management system using a mixture of methods and techniques to obtain a more comprehensive and richer understanding of the phenomenon.

We adopted the case study, phenomenology, the survey and the review design. The reason for taking a group of designs lay in the advantages deriving from their collaborative effort. A case study is defined by a single event such as a person or social group or its detailed record (Popenoe, 1993, p. 44). The design uses both the ordinal and nominal scales in recording and analyzing data, which makes the information simple to understand. Participant and nonparticipant methods can also be applied under the design. The case study design, like phenomenology, is qualitative. Furthermore, case study methodology is a strategy for researchers to study complex phenomena within their context (Stake, 1995, Merriam, 2001). Importantly, the adoption of a case study made it possible to fuse into the study the documentary review approach into the 'archival records' (Performance Appraisal Forms), as Wikipedia (2003) suggests. Influenced by Boyd et al. (1981) who remark that observation is, "...a process of recognizing and noting people, objects and occurrences rather than asking for information," (p. 125), the focus of the observation was to be able to recognize and note occurrences, not in order to ask questions. To this end, the construction of reality was based on people's own experiences. Teacher interviews and the non-participant observations made it possible to have triangulation of methods and data, which assisted to build on the trustworthiness of the outcomes.

Phenomenological design on the other hand allowed us to understand how the subjects interpreted their world in relation to Performance Management system (PMS). The design uses questionnaires as well and observation guides. This facilitated an attempt to be part of the 
social group but trying to remain ethical about the data collection procedure. Interestingly, phenomenology asks us to set aside all previous habits of thought ... to learn to see what stands before our eyes," (Hussert, 1931, p. 43 cited in Crotty, 1998). Moreover, the method allowed for the structured and unstructured interviews to be carried out while the researchers eliminated prejudices or assumptions (Moustakas, 1994). The review design was included as a method of research because "...literature review is another form of a research design." (Wikipedia, 2013). A study of the appraisal forms had to be undertaken in order to learn from them the potential relationship between the stated outcomes in the forms and the level of teacher understanding of the system and their response to policy requirements. Of equal importance, the survey design was included because of its suitability in situations where the population to be studied is large and geographically scattered.

The study population comprised of 9355 primary schools and 4641 teachers in 647 primary and 229 secondary schools respectively, in the eight districts of the Midlands province of Zimbabwe. The population also included respective school heads totaling 867 . We employed a multi-level sampling technique to eventually select the participants. First, using the lottery technique, two $(25 \%)$ of the eight districts in the Midlands province of Zimbabwe were randomly selected for study, which gave each district an equal chance to be selected. Following the same procedure, we sampled 48 primary and 17 secondary schools from the two districts, making a sample size of 50\%. From the schools we then randomly sampled a total of 144 teachers at the rate of 3 teachers per school with equalization of an additional 1 teacher for large schools, ending with a sample size of $5.2 \%$ and $3.5 \%$ for primary school and secondary school teachers respectively. By virtue of heading a school included in the sample, we purposively selected also respective school heads to be participants, and also district education officers for the two districts studied. Ethical guidelines on informed consent, voluntary participation and confidentiality, among others, were complied with.

A triangulated mixed methods approach was employed to collect data where we used questionnaires, interviews, non-participant observation and review of the Appraisal Forms. The mixed methods approach assisted in meeting data and methodological triangulation, leading to qualitative and quantitative deepening of evidence and subsequent analyses. We analysed quantitative data using descriptive statistics (numbers $[\mathrm{N}]$ and corresponding percentages [\%]), while we employed thematic analysis to make meaning out of qualitative data.

\section{The Role of the Supervisor}

\section{RESULTS AND DISCUSSION}

The role of the supervisor is central to the implementation process of the Performance Management System. Table 1 below is based on the submission by teachers and the school heads that we gathered through the questionnaire and interviews. Of interest, in the responses, is their lack of focus on the Performance Management System's demands. 
Table 1

The Role of the Supervisor in Performance Management - Quantitative Data

\begin{tabular}{|c|c|c|c|c|c|}
\hline \multirow{2}{*}{$\begin{array}{l}\text { How school heads perceive } \\
\text { the role of the supervisor } \\
\qquad N=65\end{array}$} & \multicolumn{2}{|c|}{$\begin{array}{l}\text { Responses } \\
\text { by item }\end{array}$} & \multirow{2}{*}{$\begin{array}{l}\text { How teachers perceive the } \\
\text { role of the supervisor } \\
\qquad N=36\end{array}$} & \multicolumn{2}{|c|}{$\begin{array}{l}\text { Responses } \\
\text { by item }\end{array}$} \\
\hline & $\mathrm{N}$ & $\%$ & & & $\%$ \\
\hline $\begin{array}{l}\text { to help the members to set the } \\
\text { Key Result Areas }\end{array}$ & eir & 31 & $\begin{array}{l}\text { to enforce the implementation } \\
\text { process }\end{array}$ & 15 & 42 \\
\hline $\begin{array}{l}\text { to help teachers achieve their } \\
\text { set objectives }\end{array}$ & 30 & 46 & to supervise teachers & 24 & 67 \\
\hline $\begin{array}{l}\text { to monitor whether plans are } \\
\text { being followed }\end{array}$ & 40 & 62 & to dictate what should be done & 20 & 56 \\
\hline $\begin{array}{l}\text { to supervise teachers } \\
\text { to evaluate teachers for } \\
\text { promotion and salary rise }\end{array}$ & 50 & 77 & $\begin{array}{l}\text { to monitor } \\
\text { to evaluate }\end{array}$ & $\begin{array}{l}10 \\
15\end{array}$ & $\begin{array}{l}28 \\
42\end{array}$ \\
\hline
\end{tabular}

Evidence revealed that $31 \%$ of the school heads saw their role as that of helping teachers set objectives. $46 \%$ perceived the role of the school head as giving help to teachers to achieve their set objectives. $62 \%$ of the school heads were focused on the monitoring of the plans. $77 \%$ viewed their role in terms of supervision, and $92 \%$ were evaluation oriented. The role of the supervisor, from the school heads' perspective, can be understood from a dichotomous point of view. The first, is clinical in nature because teachers are collaboratively assisted to perform, and the other is more of a control mechanism; the teacher is viewed as a curriculum worker who should be supervised to get things going, and then assessed in order to place a value for decision making purposes. The approach is deeply rooted in the scientific management principles where the concern is more on the results with little concern on the individual who should produce those results. This approach can be a recipe for the development of conflict between teachers and supervisors. Of concern also is the lack of understanding by $62 \%$ who focused on the monitoring role. It is worth noting that $92 \%$ think more of the rating that they award when they evaluate teachers' performance. They are silent on the developmental aspect which, in fact, is the corner stone of Performance Management System. The approach in the first two roles is more progressive than the last three which tend to cause friction and resistance to the system. If it can be assumed that the supervision the school heads were referring to was of the formative type, then, that supervision could be positively perceived. Notably, 67\% were agreed that school heads supervised teachers and, on further probing, teachers stated that summative supervision rooted in the scientific principles was the major concern of the school heads. On the other hand, $42 \%$ of the respondents said that school heads were there to enforce the implementation process. Unfortunately, the enforcement is synonymous with policing and generally is a recipe for the development of confrontational attitudes very much inclined towards the dislike, not only of the supervisor but also of the phenomenon that supervisors are supposed to sell to teachers. Besides, the other $56 \%$ of the 
teachers said supervisors dictated things while $28 \%$ viewed them as monitoring agents. The other $42 \%$ were of the opinion that supervisors evaluated the work of the teachers.

The interview data confirmed that the role of the supervisor is viewed negatively. The dictatorial stance by the supervisors was confirmed to a larger extent during the nonparticipant observation (Interview notes, 24 September, 2008 and 25 March, 2009). The conclusion that can be drawn in situations where the supervisor's role is perceived negatively is that the system is bound to suffer. Of necessity, we need to take Marr (2008: 1) seriously when he says, "Avoid a command and control approach and ensure people across the organization are involved in and engaged with the process of Performance Management." This is the only way the system could be developmental. In the non-participant observation meeting of 24 September, 2009 we noted that the school head did much of the talking, combined the review and the appraisal and, the sitting arrangement exhibited superior-subordinate relationship that characterizes a controlled atmosphere that is not conducive to staff development. On 30 October, 2009 a good discussion took place between a teacher and a Head of department. The venue was appropriate and the meeting was conducted in a business-like manner. There were references to the quality of assignments in the children's books, quality of the content and syllabus coverage, quality of marking and general neatness. The final rating was determined by a clearly defined work output. We wished to see many of such reviews but it became rare to have it repeated elsewhere. No wonder why some teacher remarked, "some school heads are heads by appointment and not by qualification" (Interview notes, 8 March 2009).

There was evidence that school heads dictated issues and teachers were expected to comply. This is contrary to the clinical method of assessment. One teacher said it clearly in an interview, "I battle through to please the supervisor, I am forced admittedly to do it, I make attempts to comply with the employer's demands, and to survive on the job I do as assigned and understand later" (Interview Notes, 31 September, 2008 and 10 October, 2008)

The triangulated results from the data that were collected from the two Districts have revealed a perfect agreement that supervision in Performance Management System in the areas studied was not developmental.

\section{Implications from the Coercive Leadership Approaches}

In the quantitative teacher responses and the qualitative teacher interviews, teachers were asked to clarify how they managed to handle Performance Appraisals if they found the system difficult to implement, this is what they said "I make do with what is there, I do the clerical work and copy from others and cheating, "fadza customer" [meaning please the supervisor through devious means]" (Interview Notes, 27 November, 2008 and 31 march, 2009). These are desperate expressions of negativity about the system. We cannot expect a system operating in such a context to help teachers to develop professionally. If anything, the outcome is counterproductive. In fact, when teachers were asked how they would react to supervisors who dictated things, $81.5 \%$ of them said they would resist their orders. Resisting the supervisor's instructions would entail being prepared to face the wrath. On the other hand, 18, $75 \%$ of the teachers said that they would submit to the school head's decisions. Evidently, submission does not create effective schools. Submission per se does not necessarily entail a shared vision towards Performance Appraisal. Confrontational attitudes is a source of friction. To avoid chastisement, teachers have no option but to be reactive to directives as is demanded, hence "Fadza customer, [please the master]" meaning that one should simply do as wanted by 
the leader - an attitude that is derogatory in nature. Teachers taking such a stance would have actually disengaged, and that does not yield improved performance, nor does it ensure accountability and organizational goal achievement. It seems fair to argue that supervisors may be creating a dislike of the Performance Management System to a larger extent, because of the approaches that they applied. Nhundu (1999), Marr (2008), Bange (2009), Sithole (2009) and Madekeni (2012), have all submitted that, unless supervisors are careful in the way they perform their role, Performance Management System may be dysfunctional.

Evidence from the interviews and non-participant Observation meetings revealed that Performance Management System encouraged teachers to cheat. On 31 March, 2009, in an interview, one teacher confirmed that when confronted with a difficult assignment in Performance Management System, "I cheat - Fadza customer," meaning 'do it to please the supervisor.' In the process, the teacher creates an impression that all is well when, in fact, very little will be taking place. As said by Matemba (2006: 5) "...being busy is not the same as producing results." No wonder why Matemba (2006) further writes that, "Supervisors have conducted Performance Management System for years ...but too often, activities are done for the sake of doing them; not for contributing directly to the preferred results of the organization" (p. 5). Similarly, in this study, in a non-participant observation meeting (24

September, 2008), there was a combination of the review and the appraisal of the teacher's performance all in one meeting in a single day. This is cheating also on the part of the supervisor because the value of the review is lost and buried. Besides, cheating on its own does not give one a peace of mind - frustration is its outcome. The mental disposition does not end with frustration but goes beyond to seek freedom from the source of that frustration, and in the process the negative attitudes towards Performance Management take the center stage.

\section{Supervision Approaches employed in the Schools}

From the Education Officer interviews and non-participant observation meetings, evidence revealed that supervisors dictated the process and outcomes in the reviews and Appraisal meetings. In the appraisal meeting (24 March, 2009) supervisors dominated the discussions and at the end of it they gave the final decision, and that could not be challenged by the teachers. The Education Officer (Interview note, 17 November, 2008) also mentioned that because of transport problems they asked school heads to carry their files to District Offices much against policy requirements. These approaches were dictatorial and are characteristic of the scientific management models where the command structure should be adhered to. Unfortunately, the approach does not yield the needed results because of its de-motivating factor that leads workers to disengage.

In an interview (notes of 31 September, 2009) one teacher submitted that, "We are being asked to implement things we are not involved in deciding". On the same date another teacher submitted, "As teachers we should be consulted on all matters that affect us" (Interview notes, 24 September, 2008). Teachers desired to be consulted as a matter of policy. Teachers were requesting that democratic leadership styles be applied in the way they are supervised. By implication, supervisors seemed to lean more towards the scientific management model, and with that very little progress should be expected because of low morale. Models that regard workers as machines and purely focus on results are not development oriented. Needed is a direct focus on clinical models where workers are viewed as asserts that should be developed through a process of social interaction and recognizing that both parties are equals. 


\section{The Capacity of School Heads to Do Performance Appraisals}

Quality performance and the capacity of the school heads are critical factors that determine the success or failure of all school initiatives, Performance Management System included. The implementation process requires that school heads guide teachers and continually update their skills and initiative especially if the teachers are new in the system. For all this to happen, school heads should have the know-how. If this is not there, then the system is likely to face implementation challenges. Table 2 presents teachers' experiences regarding the capacity of school heads towards the system.

Table 2:

Perceptions Regarding the Capacity of School Heads to Do Performance Appraisals

The nature of perceptions

$\begin{array}{cc}\begin{array}{c}\text { School heads } \\ \text { responses }\end{array} & \text { Teacher } \\ \mathrm{N}=65 & \mathrm{~N}=202\end{array}$

$\mathrm{N}=65 \quad \mathrm{~N}=202$

\begin{tabular}{lcccc} 
& $\mathrm{N}$ & $\%$ & $\mathrm{~N}$ & $\%$ \\
Supervisors are better informed than their teachers & 27 & 41 & 55 & 27 \\
Some supervisors are at the same level as their teachers & 18 & 28 & 50 & 25 \\
Some teachers may be better than their supervisors & 20 & 31 & 97 & 48 \\
& & & & \\
\hline Total & 60 & 100 & 204 & 100 \\
\hline
\end{tabular}

It is surprising that only $41 \%$ of the school heads in Table 2 indicated that they were better than the teachers. However, the response may be presenting a true picture because only $27 \%$ of the teachers agreed with the school heads in the $41 \%$ category. Both groups of informants concurred that some school heads were at the same level as the teachers $-28 \%$ of the school heads and $25 \%$ of the teachers. $31 \%$ of the school heads and $48 \%$ of the teachers submitted that teachers may actually be better than the school heads. This allegation is based on the lack of assistance from the school heads when teachers need to be assisted. Based on the biographic data, the few school heads who were probationers did not receive the initial training of 1994 and those who had been trained could have forgotten what had been said then or could have retired. In fact, one education officer whom we interviewed said that school heads needed constant reminding on key features of the Performance Management System. Evidence from the interviews conducted with the Education Officers (EOs) pointed towards the absence of meetings and workshops to update school heads on Performance Management System, a scenario that logically would manifest in a school context.

EOs who are supposed to staff develop heads went further to justify the reasons why they failed to perform that task. Evidence revealed that they were handicapped by the lack of resources to carry out the staff development function (Interview Notes, 10 October, 2008). Based on the submissions from the people who live the Performance Management experience, and are supposed to monitor the implementation process of the system, the study concludes that school heads were limited in terms of capacity purely because they too were not being capacitated to effectively discharge their duties as was demanded by policy. In view of this, the 
policy expectations that school heads would staff develop teachers in Performance Management remain a theoretical proposition than practical because capacity was just not there. This could be the reason why one EO in an interview said that one teacher refused to do Performance Management System, openly shouting to the school head, "Leave me alone!" (Interview notes, 10 October, 2008). The open refusal by the teacher can be equated to that of the worker in a digital company who said, "I would rather kick bricks with my bare feet than do appraisals," (Rowe, 1994, in Beach \& Chadwick, 2004, p. 253). Another EO (10 October, 2008 ) said, "Teachers generally have respect for authority but when it comes to Performance Management System there were contradictions whose parameters we may not delimit".

The tendency to resist doing work that challenges one's knowledge base tends to be very high among all people. This could be the reason why one teacher resisted doing a system that she said was disliked by authorities. Matemba (2006) had earlier own complained that senior officers had a negative attitude about the system. It could have been that the lack of EO capacity was fueling the anti- system attitude. The point that Waal (2007) makes about managers [school heads, and can be extended to include EOs] is of interest here. He states that "If management fails to be ...a role model by regularly addressing Performance Management System, organizations will have a tough time fulfilling their potential" (p. 12). We fully support the observation by Maodza (2010) that if the heads are not given the know-how and remain "Heads by appointment and not by training" they will not positively influence the system. Training of the school heads is a necessary process if teachers are to move towards an acceptable Performance Management environment. As things stand, the lack of skills in Performance Management System is creating the mismatch between policy demands and the way teachers respond to that demand. Mutatis mutandis, we go backwards to the lack of resources that are creating the lack of skills training. As viewed by Rai (2009) the coaching Model requires that the supervisor identifies weaker subordinates to be given extensive guidance to enable them to achieve the expected results. However, in the non-participant observation meetings that we attended there was no reference to a guidance plan to improve the workers.

The supervisor limitation is loud and clear. The only way to resolve the supervisor limitation is through thorough training so that school heads become school heads by qualification and not by appointment. Teachers are concerned that they are made to contend with the supervisor's opinion and ratings because they are not consulted. Needed therefore, is to consult them so that they participate in shaping the system. The only condition that is necessary for the system to belong to those who are called upon to implement it is their involvement at the planning stage. Adequate consultation is a necessary attitudinal change tool. Short of it, the rejection of the innovation should be anticipated. Supervisors who exert their opinion do so because of a limited expertise base. An acceptable approach to the system should entail thorough training of the supervisors to upgrade their knowledge and performance for appraisal assessment ratings to be meaningful.

\section{CONCLUSION}

Due to the lack of proper training school heads tended to be dictatorial in their approach to supervision. This has tended to cause teachers to resent the programme or to use devious means, among them cheating in order to meet the demands of Performance Management System. Similarly, in the interview meetings, it was observed that supervisors on the main dominated the review and appraisal discussion. These unorthodox approaches did not help to facilitate the staff development of the teachers, thus further creating problems of conception of 
the demands of the system on the teachers. A number of proposals were made, among them that teachers be consulted on these issues in order to facilitate sound planning.

\section{Participants Voices Regarding Assessment}

\section{RECOMMENDATIONS}

Supervisors have limitations that they find difficult to contend with. To cushion the supervisory work, participants in the study suggested the following:

- The education supervisory machinery from education officers to the Senior teacher and Head of Department should be adequately trained and equipped;

- Ministry should start something better understood;

- Teachers as implementers should be consulted on things that affect us;

- Do not give us supervisors by appointment and lacking qualification; and

- Authorities should be committed to the system and be capacitated. (Interview Notes, 30 September, 2008; 22 January, 2009 and 31March, 2009).

\section{ACKNOWLEDGEMENTS}

This article draws from doctoral thesis work entailing supervisor-supervisee collaborative effort as scholarly partners on the learning tour. Both authors contributed equally to the shape and outcome of this article.

\section{References}

Ayee, J. R. A. (2001). Civil Service Reform in Ghana: A Case Study of Contemporary Reform Problems in Africa. African Journal of Political Science, 6 (1), 1-4.

Bange, C., Marr, B. \& Bange, A. (2009, July). Current Changes and Future Direction. A Global Survey of the Maturity of Performance Management Processes .German: BARC, Wurzburg.

Boyd, H. W., Westfall, R., \& Stasch, S. F. (1981). Marketing Research: Test and Cases. Georgetown: Richard D. Irwin Inc.

Cardno, C. (2005 November). Performance Appraisal Evaluation: Report of Findings and Recommendations. Accra, Ghana: USAID.

Darling, L., Hammond, \& Richardson, N. (2009). Teacher Learning: What Matters? Association for Supervision and Curriculum Development, 66 (5), 47-53).

Crotty, M. (1998). Foundations of Social Research: Meaning and Perspectives in the Research Process. London: SAGE.

de Waal, A. A. (2007). Is Performance Management Applicable in Developing Countries?: The Case of a Tanzanian College. International Journal of Emerging Markets, 2 (1), 69-83).

Dzimiri, W. \& Mkosana, C. (2015). Teacher Experiences of Permance Management System in Zimbabwe: Focus on Training. The Dyke, Journal of the Midlands State University. Vol. 9 (2) (In press).

Machingambi, S. (2013). Teachers Perceptions on the Implementation of the Performance Management System in Zimbabwe. International Journal of Education Science, 5 (3), 217-225.

Madekeni, A. (2012). Implementing Results-based Management System in Zimbabwe: Context \& Implementation for the Public Sector. In International Journal of Humanities \& Social Science, Vol. 2 No. 8 (Special Issue - April 2012). Harare: University of Zimbabwe, Zimbabwe.

Maodza, T. (2010). Permanent Secretaries to be Judged on Results: A Report on the Public Sector. Harare: Public Service commission.

Marr, B. (May, 2008,). What's the Score in the Public Sector? Rethinking the Way we Measure and Manage Performance. A Paper Presented at UNICOM Conference, London.

Matemba, D. (2006 June to July). Participant Report on Performance Management for the Public Sector. A Paper Presented at a Performance Management Public Sector Course Held in Singapore, Singapore. 
Merriam, S. B. (2001). Qualitative research and case study applications in education. San Francisco: Jossey-Bass.

Mestry, R., Hendricks, I., \& Bisschoffs, T. (2009). Perceptions of Teachers on the Benefits of Teacher Development Programmes in South Africa. South Africa Journal of Education. 29 (4), 475-490.

Miner, J. B. (2005). Organisational Behaviour 1: Essential Theories of Motivation and Leadership. New York: Routledge.

Moustakas, C. (1994). Phenomenological Research Methods. London: SAGE.

Musingafi, M. (2007, December, 10). Improving Performance. The Case of the Zimbabwean Civil Service.(Unpublished Master's Thesis). Harare: Zimbabwe Open University.

Ngwenya, T. (2002). An Investigation into Teacher Perception on Appraisal in Gokwe Central Cluster Area. (Unpublished .Bachelor of Education Dissertation).Harare: Zimbabwe Open University, Zimbabwe

Nhundu, T. J. (1999). Assessing Teacher Performance: A Comparison of Self and Supervisor Ratings on Leniency, Halo and Restriction of Rating Errors. Lusaka: University College of Distance Education, Zambezia.

Popenoe, D. (1993). Sociology. New Jersey: Prentice Hall.

Rai, R. K. (2009, October 4). Performance Management System. Retrieved March 3, 2012, from http://rohits21989.blogspot.com/2009/10/performance-management-system.htm/

Ringue, A. A. (2002). Middle School Principal's Perspectives in Georgia Educational Reform Policies. Unpublished Dissertation. Atlanta, Georgia.

Robbins, S. P. \& de Cenzo, D. A. (1995, January). A Three Day Course for Supervisors. In the SIDA Funded Projects. (1998). Harare: Zimbabwe.

Robbins, S. P. (2007). Organisational Behaviour: Global and Southern African Perspectives. Cape Town: Pearson Education, South Africa.

Sergiovanni, T. \& Starrat, R. (1993). Supervision: A re-definition. New York: McGraw-Hill.

Stake, R. (1995). The art of case study research. Thousand Oaks: SAGE Publications.

Zimbabwe Public Service Commission (2009). Results Based Personnel Performance Management System Appraisal Module. Harare: PSC. 